\title{
A test of the Virginia opossum's preference for sweets
}

\author{
W. T. JAMES \\ University of Georgia, Athens, Georgia 30602
}

\begin{abstract}
Although a great deal is known about the food habits of the opossum, Didelphis virginiana, very little is known about its interest in sweets. The present study was designed to determine if opossums have a preference between plain water and a $5 \%(w / v)$ sugar solution. Three animals were tested; two of them had been reared in the laboratory, and one had been captured in the wild some months before the test. The animals were kept in large cages and given a choice for 1-h daily tests between bottles containing the solutions. There was no doubt that the animals preferred the sweetened water. Since the wild animal behaved in the same manner as the laboratory-reared animals, previous feeding experience did not seem to affect the results.
\end{abstract}

In an attempt to investigate the learning ability of the Virginia opossum during the last few years at the University of Georgia, a great deal has been determined about rearing and feeding the animals (James, 1958, $1959,1966)$. The early studies were done with wild opossums, but the wild opossums never became amenable to handling, and they were very inhibited during the training procedure. It was then decided to attempt to remove the animals from the mother at an early age and to feed them by bottle until they were old enough to feed themselves. This procedure has proved highly successful, and the animals become tame and as easy to handle as tame kittens.

Another problem was the type of food to give the opossum. Hartman (1952) had recorded the types of food the animal eats in the wild. Based on stomach analysis, the foods include the following: insects, mammals, reptiles, seeds, fruits, invertebrates, birds, and eggs. Atkinson (1935), who began feeding opossums in her yard in California, also found that they would eat a wide variety of foods, including meats, cake, fruits, and all varieties of food left from the table. Most of these are not accessible in the laboratory, however. Since the University of Georgia has a large colony of dogs, it was decided to feed the opossums moistened dehydrated dog food plus canned horse meat or any other type of meat that could be obtained from the university kitchens. This food was satisfactory in every respect, and the animals have been maintained on this assortment of food for many years.

One question asked by visitors to the laboratory concerned the preference for sweets on the part of the opossum. Hunters often find opossums in the persimmon tree. The ripe persimmon has a rather sweet taste. and it was thought perhaps the opossum would choose sweet food over any other without sugar.

In order to find out more about this question, a number of tests were conducted on the opossum's preference for plain water in contrast to water containing $5 \%$ sugar.

Since research has been more successful with animals reared in the laboratory than with wild animals, a number of opossums reared in the laboratory were used in the tests. The animals were obtained by trapping a pregnant female in May of 1966. The young were removed from the pouch as soon as they were old enough to leave the nipples and were bottle fed at first by a small doll bottle containing milk and strained meats used as baby food. Within a short time, they were shifted from bottle to eating from a pan. Since the gestation period for the opossum is around 13 days, and they remain in the pouch for 62 days, they were around 30 days of age when removed from the mother. Animals reared by this procedure have proven to be amenable to handling and responding in various types of training apparatus. Eight animals were taken from the mother, and all survived. Two of these were used in the sugar preference tests at 2 years of age. One wild animal around 1 year of age was also used to determine whether those reared under natural conditions would perform in the same manner, since their food likely has been quite different from that of animals reared in the laboratory.

\section{METHOD}

The animals were kept in cages $2 \mathrm{ft} 4 \mathrm{in}$. square, with shavings and paper on the floor for bedding. Two 200-cc bottles were placed in each cage, one on the right of the front side and one on the left. A small glass tube projected through the wire of each cage. The animals learned within a short time to lick water from the tubes. During the tests, one bottle contained plain water, and the second one was filled with $5 \%$ sugar water. The animals were tested for $1 \mathrm{~h}$ each day during the afternoon for a large number of readings. The bottles were shifted before each daily test so the animal could not respond to position. At the beginning of each trial, the animal would sample both bottles and then select the one of its choice. Animal 5 was 
Table 1

The Average Plain and Sweet Water Intake (in Cubic Centimeters) for Three Opossums

\begin{tabular}{ccccc}
\hline & & \multicolumn{2}{c}{ Intake } & \\
\cline { 3 - 4 } Animal & $\begin{array}{c}\text { Number of } \\
\text { Tests }\end{array}$ & Water & Sugar & $\mathrm{t}$ \\
\hline 5 & 30 & 2.4 & 86.96 & $4.39 *$ \\
6 & 27 & 4.3 & 119.00 & $14.25^{* *}$ \\
7 & 38 & 3.8 & 138.80 & $17.67^{* *}$ \\
\hline
\end{tabular}

Note-Animal 7 was the wild animal. $\quad * p<.001 . \quad * *<<.0001$.

tested for 30 days, Animal 6 for 27 days, and Animal 7 (the wild opossum) was tested for 38 days.

\section{RESULTS}

The results of the tests are tabulated in Table 1. There does not seem to be any doubt about the ani- mals' preference for the sweet water. Since the wild animal performed in the same manner as the laboratory animals, the preference could not be based on difference in food experience.

\section{REFERENCES}

Atrinson, A. A. Br'er possum, hermit of the lowlands. National Geographic Magazine, 1935, 103, 405-418.

Hartman, C. G. Possums. Austin: University of Texas Press, 1952.

JAMES, W. T. Conditioned responses in the opossum. Journal of Genetic Psychology, 1958, 93, 179-183.

James, W. T. Behavior of the opossum in the Fink Arrow Maze. Journal of Genetic Psychology, 1959, 94, 199-203.

JAMES, W. T. A study of form discrimination in the opossum. Journal of Psychology, 1966, 64, 193-198.

(Received for publication April 28, 1980.) 